\title{
Application of numerical modelling in stream metrology on the example of primary air installation
}

\author{
Mirosław Kabaciński*l, Janusz Pospolita ${ }^{l}$, Janusz Polak $^{2}$, Piotr Adamus ${ }^{2}$, Antoni Salij ${ }^{3}$, \\ Kazimierz Sumara ${ }^{3}$ \\ ${ }^{1}$ Opole University of Technology, Mechanical Department, Poland \\ ${ }^{2}$ Zakłady Remontowe Energetyki Katowice S.A., Poland \\ ${ }^{3}$ ENEA Elektrownia Połaniec S. A., Poland
}

\begin{abstract}
Measurements of stream flows are very common in the power industry. High parameters of the fluid, its impurities or the complexity of the flow installation make often such measurement problematic. Flow disturbances are a factor that significantly increases measurement uncertainty.

The paper presents an example the measurement problem solution based on mathematical modelling and digital flow simulation. The problem was the measurement of the air stream in a complex mill air flow installation. A measuring system based on a probe averaging dynamic pressure has been developed. The location of the probe was determined by numerically modelling the flow in the considered section of the mill air installation. Monthly observations of the measuring system operation confirmed its high usefulness in the operation of the mill installation.
\end{abstract}

\section{Introduction}

Modern power boilers comprise a variety of measuring equipment applied to ensure their reliable exploitation. Measuring systems constituting elements of automatic control systems are applied both for boiler regulation as well as to ensure the correct performance of the boiler equipment. The measurements of the flow rates of fluids play a very important role among a number of measured quantities. For many reasons, in the case of boiler equipment such measurements are difficult to undertake and perform. These difficulties result from a number of reasons, first of all, from the relatively high parameters of fluids, including fresh steam, steam and water in the boiler circulation as well as primary and secondary air. Secondly, the flow rates of the fluids are considerable and, as a result, the dimensions of the channels are also large, in the case of air and exhaust gases, they have large diameters and rectangular cross-sections. Thirdly, the air circulating in the system can be contaminated by the ashes accumulated in the air-flue heat regenerators.

Another problem occurring in flow installations, in particular in air ducts, large power boilers, is associated with too short straight sections of pipes upstream of the flowmeters [1]. This applies to both ducts carrying primary and secondary air. An additional difficulty is associated with the complexity of the flow installation, as well as specific requirements 
related to the demand associated with flow distribution to low-emission burners, secondary air, as well as air routed to feed the OFA, SOFA or ROFA nozzles. A completely separate problem is concerned with the measurement and possible adjustment (correction) of the flow of the coal powder mixture and the primary air in the air-powder flow installations. In the installations with considerable air temperatures, the most common designs employ differential pressure flowmeters such as nozzles (including special constructions and Venturi tubes) as well as flow averaging Pitot tubes [2, 3, 4]. In particular, the latter category provides an interesting alternative to the use of orifice plates. Practically, they result in a negligible permanent pressure loss. The cost associated with their installation is definitely lower than the one associated with the production and installation of Pitot tubes, especially in flow installations in boilers. Their operation at relatively small values of differential pressure is enabled by the differential pressure transducers available in the market with high reliability and low measurement uncertainty [5].

The task that is often faced in boiler installations is associated with the selection of the most suitable location of the probe in the conditions of a limited number of alternatives for its installation.

The mathematical and numerical modelling of fluid flow [6-8] through the analysed flow system provides a practical tool in this context. In the case of such a theoretical analysis, it is possible to face various obstacles (limitations). The systems applied in industrial practice are usually complex in terms of their geometry and they normally require the development of three-dimensional geometry. In addition, such systems often comprise a variety of elements applied for control and cut-off purposes. Faithful reproduction of the geometry of such systems often requires detailed measurements employing surveying techniques, including the measurement of wall thickness and surface roughness. Sometimes problems associated with determining the boundary conditions at the inlet and outlet of the flow system are faced in such analysis. They may result from the location and operation of the fans. An adequate selection of such conditions is related to the knowledge regarding velocities and pressure distributions virtually along the entire cross-section of the installation [9].

The conducted research demonstrates the possibility of implementing small modifications to the design of such installations which can lead to a significant improvement in the accuracy of the measurements.

We can mention that the results of calculations can affect the design and implementation of measurement systems serving primarily for the control the operation of machinery and equipment. The level of uncertainty of the obtained results, which is slightly different from the forecast is often not considered as a priority, as the most important aspect is related to the repeatability of the measurements. As far as possible, these non-standard measuring systems should be verified for example with regard to the balance of mass and energy of the equipment or by employing measurements of velocity in a given cross-section by application of a grid method.

This paper contains a study involving an example of such an operation based on the installation applied for measuring the volume of primary air fed to the MKM33 coal mill at ENEA Elektrownia Połaniec S.A.

\section{Analysed flow system}

The flow system applied to feed air into a coal mill MKM33 is presented in Fig. 1. A $\phi 700 \mathrm{~mm}$ duct from a mill fan divides into two $\phi 1000 \mathrm{~mm}$ pipelines used for feeding the air into a pyrite chamber and nozzle ring. The mass flow rate of the air varies in the range from $32 \cdot 10^{3} \mathrm{~m}^{3} / \mathrm{h}$ to $108 \cdot 10^{3} \mathrm{~m}^{3} / \mathrm{h}$. The air overpressure applied in the calculations was equal to $7.85 \mathrm{kPa}$, and the temperature was taken to be equal to $322^{\circ} \mathrm{C}$. Initially, this system comprised a flowmeter with a flow averaging probe at the outlet duct from the fan, but due to large and 
irregular air velocities and vibrations generated by the air flowing around the sensor, common failures occurred to the probe. Therefore, an attempt was made to determine a new, technically feasible location of the probe between the mill fan and the coal mill. This was due to the fact that an adequate location could not be found upstream of the mill fan.
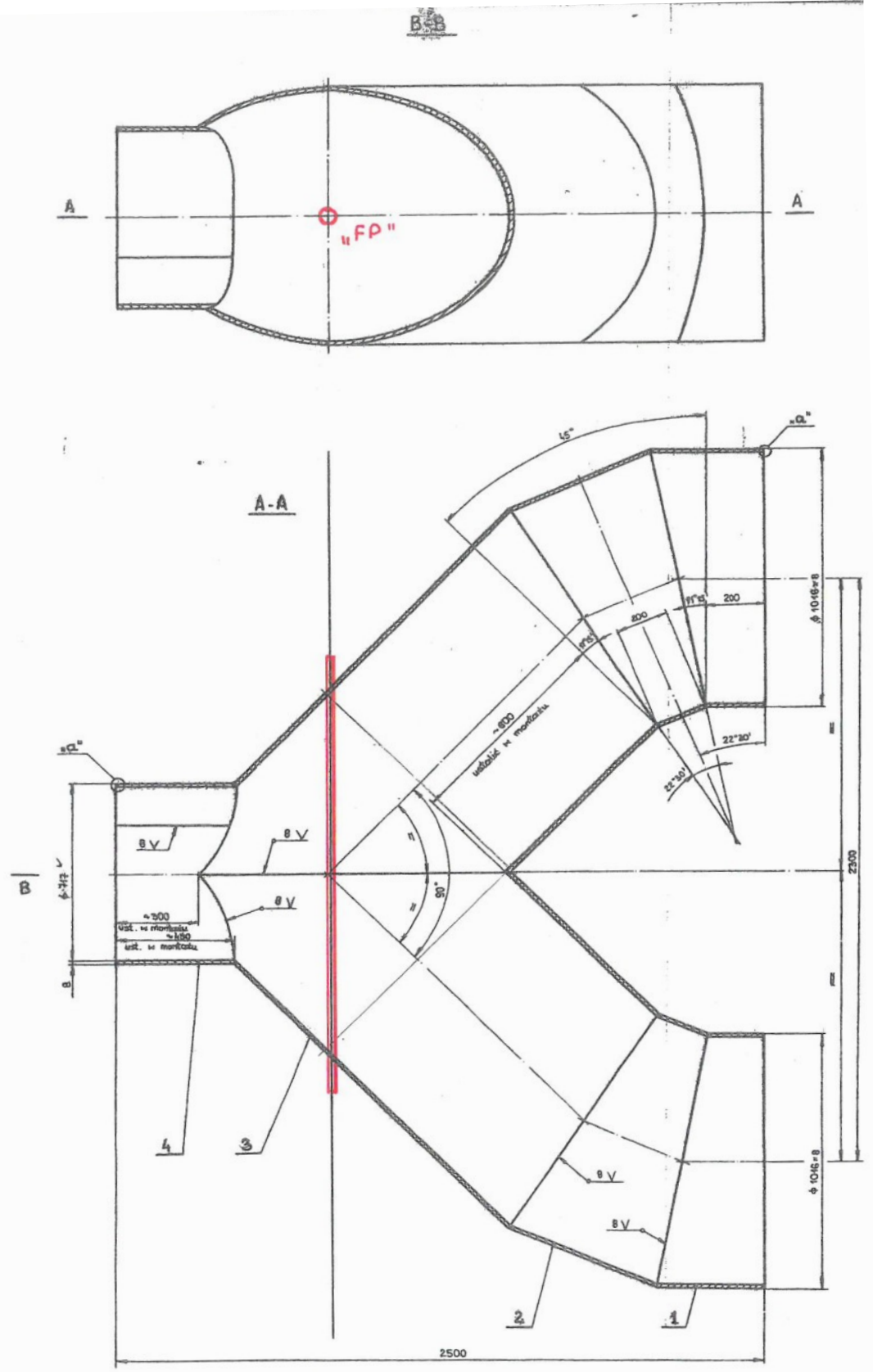

Fig.1. Analysed flow system 


\section{Mathematical model, calculation procedures, examples of results}

In the analysed area, it was assumed that the flow is stationary and three-dimensional. The mathematical model was based on equations of motion (1), equation of continuity (2) and turbulence model (5) and (6).

These equations take the following form [10]

$$
\rho \frac{\partial \bar{U}_{i}}{\partial t}+\frac{\partial\left(\rho \bar{U}_{i} \bar{U}_{j}\right)}{\partial x_{j}}=-\frac{\partial p}{\partial x_{i}}+\frac{\partial}{\partial x_{j}}\left[\mu_{e f}\left(\frac{\partial \bar{U}_{i}}{\partial x_{j}}+\frac{\partial \bar{U}_{j}}{\partial x_{i}}\right)\right]
$$

and continuity equation

$$
\frac{\partial\left(\rho \bar{U}_{i}\right)}{\partial x_{i}}=0
$$

The quantity $\mu_{\mathrm{ef}}$ forms the effective viscosity, which is given by the total of molecular $\mu$ and turbulent viscosities $\mu_{\mathrm{t}}$

$$
\mu_{e f}=\mu+\mu_{t}
$$

The turbulent viscosity is derived on the basis of the $\mathrm{k}-\varepsilon$ turbulence model

$$
\mu_{t}=\rho C_{\mu} \frac{k^{2}}{\varepsilon}
$$

in which $\mathrm{C}_{\mu}$ is equal to 0.09 for the case of the version of $\mathrm{k}-\varepsilon$ model for the developed turbulence. The kinematic energy of the turbulence $\mathrm{k}$ and velocity of its dissipation $\varepsilon$ are derived on the basis of the transport equations, which take the form [10]

$$
\begin{gathered}
U_{x} \frac{\partial k}{\partial x}+U_{y} \frac{\partial k}{\partial y}=\frac{\partial}{\partial x}\left\{\left(v+\frac{v_{t}}{\sigma_{k}}\right) \frac{\partial k}{\partial x}\right\}+\frac{\partial}{\partial y}\left\{\left(v+\frac{v_{t}}{\sigma_{k}}\right) \frac{\partial k}{\partial y}\right\}+v_{t} \frac{\partial U_{x}}{\partial y}\left(\frac{\partial U_{x}}{\partial y}+\frac{\partial U_{y}}{\partial x}\right)-\varepsilon \\
U_{x} \frac{\partial \varepsilon}{\partial x}+U_{y} \frac{\partial \varepsilon}{\partial y}=\frac{\partial}{\partial x}\left\{\left(v+\frac{v_{t}}{\sigma_{\varepsilon}}\right) \frac{\partial \varepsilon}{\partial x}\right\}+\frac{\partial}{\partial y}\left\{\left(v+\frac{v_{t}}{\sigma_{\varepsilon}}\right) \frac{\partial \varepsilon}{\partial y}\right\}+C_{1} v_{t} \frac{\varepsilon}{k} \frac{\partial U_{x}}{\partial y}\left(\frac{\partial U_{x}}{\partial y}+\frac{\partial U_{y}}{\partial x}\right)-C_{2} \frac{\varepsilon^{2}}{k}
\end{gathered}
$$

The values $\mathrm{C}_{1}, \mathrm{C}_{2}, \sigma_{\mathrm{k}}, \sigma_{\varepsilon}$ form the respective coefficients assuming the values of $\mathrm{C}_{1}=1.44$; $\mathrm{C}_{2}=1.92 ; \sigma_{\mathrm{k}}=1.0 ; \sigma_{\varepsilon}=1.3$.

The assumptions adopted as boundary conditions involved a fully developed velocity profile with a sufficiently long inlet section. The dividing flow is routed to two junctions in a ratio of $1: 1$. Only the symmetrical part of the system representing the intersection along the junction was applied for stationary calculations. The boundary condition assuming the symmetry of flow is applied at this point. The Neumann boundary condition was applied at the end of two parallel pipelines, being in the form of the adopted value of the pressure. The condition assuming the zero value of all components of the velocity vector $U_{i}$ was adopted along the walls of the ducts.

The ANSYS/Fluent [11] software based on the finite volume method was applied in seeking the solution to the equations of this model. The numerical simulations were conducted by application of an adoption of cubic grid elements (where possible) and on tetrahedrons in the junction point of the pipelines and in the vicinity of the flow averaging probe. The number of grid elements exceeded $9.4 \cdot 10^{6}$. Mesh tests were carried out in order to render the results independent from the mesh quality. The calculations were conducted under the assumption of three mean flow velocities at the inlet equal to $23 \mathrm{~m} / \mathrm{s}, 50 \mathrm{~m} / \mathrm{s}$ and $78 \mathrm{~m} / \mathrm{s}$. 
Fig. 2 and 3 present examples of results of the calculations involving air flow in the analysed flow system.

a)

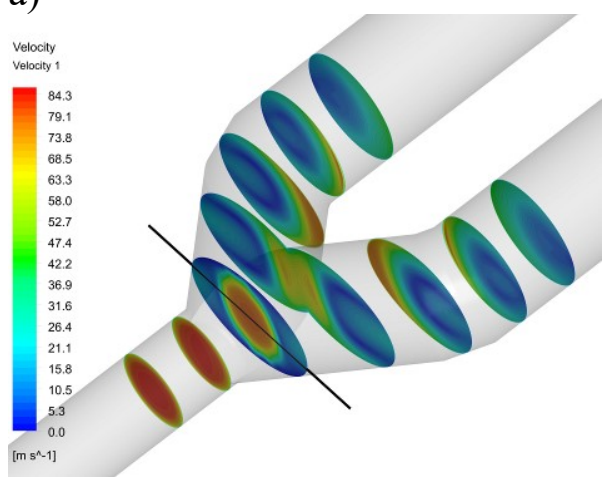

b)

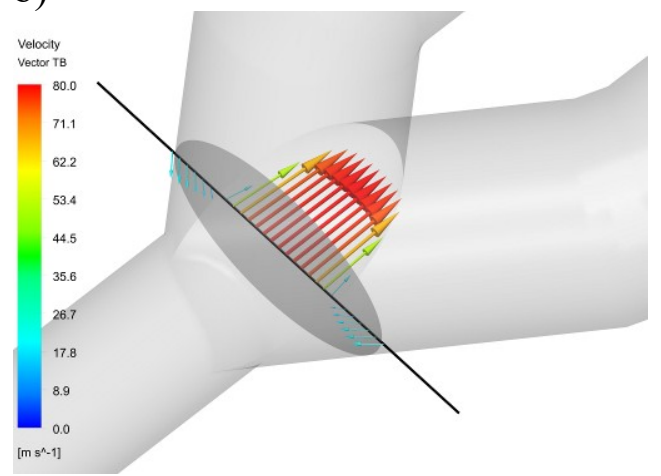

Fig.2. Air velocity in selected cross-sections of the flow system: a) field of resultant velocity, b) velocity distribution at the location spot of the probe

a)

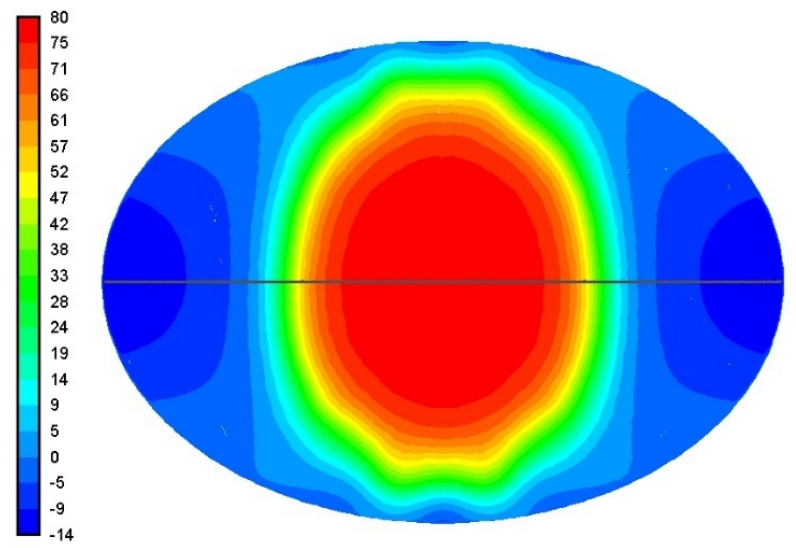

b)

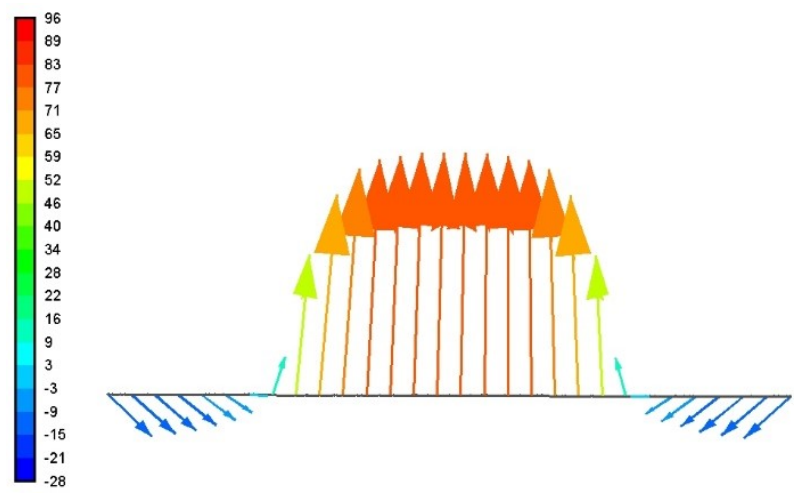

Fig.3. Velocity distribution $[\mathrm{m} / \mathrm{s}]$ in the proposed location of the probe: a) velocity field in the plane given by the probe location, $b$ ) velocity distribution at the location spot of the probe 
On the basis of the analysis of the velocity fields, a decision was made to locate the probe in the ellipse-shaped cross-section marked in Fig. 3a by with dimensions of $1400 \mathrm{~mm} x$ $1000 \mathrm{~mm}$. A decision was taken to use a TwinBar probe [12], (manufactured by ZRE Katowice S.A.), that was mounted on double sides with a flange connection and hightemperature elastic sealants applied for the protection and damping of the probe's vibrations. The TwinBar probe has a cross-section that generates vortices (and thus vibrations) with a significantly smaller intensity compared to other probes of this type [12]. The adopted crosssection, in which the probe was installed and the velocity distribution in this cross-section provided non-standard location of the pressure tapping holes. This was due to the need to carry out the measurements in the flow contained in the circle representing the so-called equivalent diameter of DN800 mm specified at the location place of the flowmeter. Due to variations in the pressure and air temperatures, the probe comprised with temperature and pressure sensors and a converter, which provided continuous correction of the flow rates measured by the flowmeter. The need to apply correction also extends to the variations caused by expansion of the pipeline in the measurement system.

a)|

d)
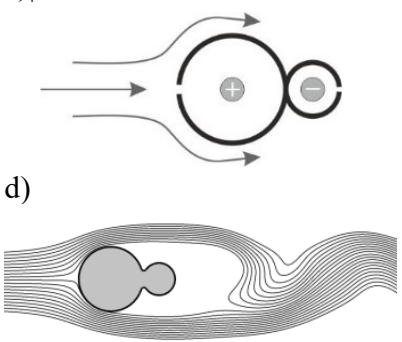

b)

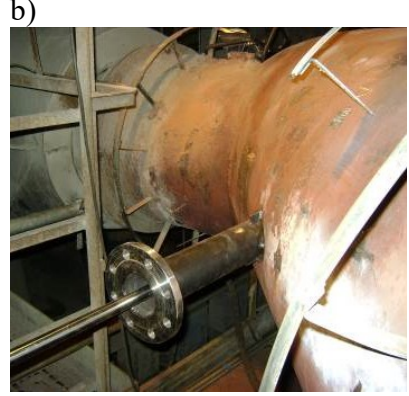

c)

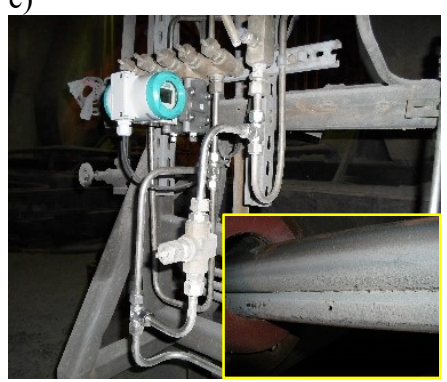

Fig.4. Cross-section of probe (a), probe prior to its installation in the flange (b), differential pressure transducer and blow-through system (c), flow around the probe (d)

The measurement system also comprised an installation that offered the possibility of cleaning blow-through in the averaging chambers and pressure tapping holes applied for pressure measurements.

The total uncertainty of the measuring systems comprising the flow averaging probes is in the range of $1-2 \%$ of the value of measurements. This value is affected by the uncertainty of determination of the flow coefficient of the probe $\mathrm{K}(0.7-1 \%)$, uncertainty of the differential pressure measurement $\Delta \mathrm{p}(0.2-0.4 \%)$, uncertainty during the determination of the gas density (usually within a very low range) and uncertainty accompanying the determination of the diameter of the pipeline. In the case of the latter quantity, uncertainty is likely to assume significant values, in particular in ducts with large diameters fabricated of sheet metal. Another problem could be associated with the maintenance of the shape of such ducts. In the conditions when probe have special applications, and when the straight sections of the pipes are not maintained for required lengths, this uncertainty can be significantly greater, and the measurement system should be calibrated, e.g. by application of a secondary standard [13]. It is also possible to determine the indications of the measurement system based on the characteristics of the fan or from the energy balance of the coal mill (the flow rate of hot air is one of the rates applied in the balance). In the present case, the uncertainty of the flow rate of the air derived by two of the last mentioned methods is already significant. The design of the flow installation results in the considerable level of error of the air flow rate by means of grid method [14]. Therefore, in the investigated case, the characteristic $\mathrm{q}_{\mathrm{v}}=\mathrm{f}(\Delta \mathrm{p})$ was based on the experimentally determined flow coefficient through the probe and the numerically modelled velocity distribution of the air flow. 
From the point of view of performance of the coal mill assembly, the investigated measurement system forms a component of the automatic regulation system of a coal mill. It provides the air flow rate that is needed for adequate powder transport and correct operation of burners. Hence, the reliability of the flowmeters and repeatability of its indications are equally important. Observations of the measuring system performed over a period of several months confirm its high practical value in the operation of the coal mill assembly.

\section{Conclusions}

The observations of the measurement systems applied in air installations in boilers applied in the power industry and the results of conducted tests lead to the following conclusions:

a) A variety of primary and secondary air installations in boilers are characterized by geometric complexity and the lack of required long straight pipe sections, which results in difficulties in the measurements of flow rates in accordance with the recommendations specified by the manufacturers of measuring equipment and guidelines given in the relevant standards.

b) The application of standard nozzles in the investigated types of installations is not only inconvenient in installation, but also leads to additional permanent pressure and energy losses.

c) It is possible to use custom metrological solutions developed for a specific installation that is developed on the basis of mathematical modelling of flow in the analysed flow system.

d) The measurement systems based on flow averaging Pitot tubes may provide some metrological solutions suitable for non-standard flow systems characterized by complex geometry.

e) The measurement system discussed in this paper that is applied in the primary air installation in a coal mill at ENEA Elektrownia Połaniec S.A. forms a novel solution, which proved effective and indispensable for the operation of the equipment.

\section{References}

[1] T. Chmielniak, J. Kotowicz, D. Węcel, Experimental and numerical investigations of the averaging Pitot tube and analysis of installation effects on the flow coefficient. Flow Meas. Instrum., 19, 301-306 (2008)

[2] R. C. Baker, Flow Measurement Handbook. University of Cambridge (2000)

[3] D.W. Spitzer, Flow Measurement: practical guides for measurement and control, ISA, Research Triangle Park (1991)

[4] M. Kabaciński, J. Pospolita, Experimental research into a new design of flow-averaging tube, Flow Meas. Instrum. 22, 421-427 (2011)

[5] https://www.automatyka.siemens.pl/docs/docs_ia/Sitrans_P_DS_III_pl.pdf

[6] B. Dobrowolski, M. Kabaciński, J. Pospolita, A mathematical model of the selfaveraging Pitot tube. A mathematical model of a flow sensor. Flow Meas Instrum., 16, 251-265 (2005)

[7] J. Pospolita, M. Kabaciński, Applicability of the chosen turbulence models in numerical investigations of flows around a body with stream separation, Chem. Proc. Engin., 27, No 3/1, 2006, 601-621 (2006)

[8] M. Kabaciński, J. Pospolita, Numerical and experimental research on new cross-sections of averaging Pitot tubes Flow Meas. Instrum., 19, 17-27 (2008) 
[9] M. Kabaciński, Experimental research on velocity profiles in selected flow systems, TASK Quarterly (2012)

[10] Turbulence Modelling: Part 2: Limitations of k-epsilon model, QNET CFD - LUZERN $\mathrm{V}(2002)$.

[11] ANSYS/Fluent 19.1, User's guide (2018)

[12] M. Kabaciński, J. Pospolita, J. Polak, Możliwości zastosowania układu walców jako podstawy konstrukcyjnej uśredniającej sondy piętrzącej, Control Engeenering Polska, 4, 26-29 (2005)

[13] M. Turkowski, P. Szufleński, New criteria for the experimental validation of CFD simulations, Flow Meas. Instrum., 34, 1-10, (2013)

[14] PN-81/M-42366: Pomiary przepływu płynu. Pomiary strumienia objętości metodami całkowania bryły prędkości, WN, Warszawa (1981) 